\title{
Jaminan Keselamatan Dalam Injil Yohanes 10:28-29 Dan Implikasinya Bagi Pengajar Pendidikan Agama Kristen
}

\author{
Yunardi Kristian Zega \\ Universitas Kristen Indonesia Jakarta \\ yunardichristian@gmail.com
}

\begin{abstract}
The doctrine of salvation (soteriology) is one of the most important doctrines in Christianity. The doctrine of soteriology needs to be understood and understood properly and correctly, so as not to lead to misleading interpretations. One of the interesting verses to discuss in the doctrine of soteriology is the assurance of salvation in the Gospel of John 10: 28-29. For this reason, in this article, the author will analyze the Gospel of John 10: 28-29 in order to provide a soteriological understanding that is in accordance with the truths contained in the text. The result of the analysis of this article is that Jesus guarantees the salvation of believers so that they do not perish forever, and God the Father also guarantees this salvation. Therefore, believers will receive the power of the Holy Spirit so that they can practice every truth that God wants in their lives. Thus, every believer can have a correct understanding of the assurance of his safety. This needs to be a concern for Christian educators, whether they teach in families, schools, or churches.
\end{abstract}

Keywords: the gospel of john; safety guarantee; soteriology; christian education

\begin{abstract}
Abstrak
Doktrin keselamatan (soteriologi) adalah salah satu doktrin yang sangat penting di dalam Kekristenan. Doktrin soteriologi perlu untuk dapat dimengerti dan dipahami dengan baik dan benar, agar tidak menimbulkan penafsiran yang menyesatkan. Salah satu ayat yang cukup menarik untuk dibahas dalam doktrin soteriologi adalah mengenai jaminan keselamatan dalam Injil Yohanes 10:28-29. Untuk itu, dalam artikel ini, penulis akan menganalisis Injil Yohanes 10:28-29 agar dapat memberikan pemahaman soteriologi yang sesuai dengan kebenaran yang ada di dalam nats tersebut. Hasil dari analisis artikel ini ialah, Yesus memberikan jaminan keselamatan bagi orang-orang percaya agar tidak binasa sampai selama-lamanya, dan Allah Bapa juga ikut menjamin keselamatan tersebut. Oleh sebab itu, orang-orang percaya akan menerima kuasa Roh Kudus sehingga mereka dapat melakukan setiap kebenaran yang dikehendaki Allah di dalam kehidupannya. Dengan demikian, agar setiap orang percaya dapat memiliki pemahaman yang benar mengenai jaminan keselamatannya. Hal ini perlu menjadi perhatian bagi para pendidik Kristen, baik yang mengajar di keluarga, sekolah, maupun gereja.
\end{abstract}

Kata Kunci: injil yohanes; jaminan keselamatan; soteriologi; pendidikan agama kristen 


\section{Pendahuluan}

Doktrin soteriologi tentang jaminan keselamatan yang dimiliki oleh seorang yang beragama Kristen, tentu dapat mempengaruhi cara berpikir dan bertingkah laku dalam kehidupan sehari-harinya. Misalnya, adanya pengaruh positif dari pemahaman soteriologi tentang jaminan keselamatan yang baik dan benar, menghasilkan orang Kristen yang memiliki kerohanian yang baik sehingga dapat memiliki perubahan hidup ke arah yang sesuai dengan kehendak Firman Tuhan. Namun, pengaruh negatif dari konsep soteriologi tentang pemahaman jaminan keselamatan yang keliru, akan membentuk orang Kristen yang fanatik, tidak mau menerima pendapat orang lain, dan memiliki tingkah laku yang berlawanan dengan kehendak Firman Tuhan. ${ }^{1}$

Orang-orang Kristen yang keliru membahas tentang jaminan keselamatan atas kasih karunia yang diberikan Allah, dalam konsep mereka yang salah dan tidak seimbang tentang pemahaman doktrin soteriologi, secara menyedihkan mereka menyelewengkan kebenaran dan menimbulkan kesalahan yang begitu besar. ${ }^{2}$ Akibatnya muncullah aliran-aliran dalam Kekristenan yang mempunyai pemahaman bahwa, orang Kristen tidak mungkin akan kehilangan keselamatannya, karena keselamatan itu anugerah Allah yang diberikan kepada umat-Nya yang bersifat kekal atau selamanya (Kol. 2:13; Ibr. 10:14; Kol. 2:13). Namun, aliran tersebut tidaklah mempertimbangkan aspek tanggung jawab moral yang diakibatkan keadaan tersebut, sehingga aliran tersebut juga berpendapat bahwa, semua dosa masa lalu, masa kini, dan masa depan, telah dimaafkan, jadi tidak perlu untuk bertobat. Mereka memiliki pandangan bahwa ketika Allah melihat manusia, Allah hanya melihat orang-orang yang kudus dan benar sehingga orang-orang percaya tidak perlu untuk bertanggung jawab atas dosa-dosa yang diperbuatnya. ${ }^{3}$

Jaminan keselamatan yang diberikan Allah seharusnya tidak memperbolehkan orang-orang percaya untuk berbuat dosa, tetapi sebagai orang percaya harus menyadari bahwa mereka akan berbuat dosa, namun dosa tersebut tidak akan menyebabkan kehilangan keselamatannya. ${ }^{4}$ Oleh sebab itu, selama orang-orang percaya masih bernafas banyak tantangan yang perlu dihadapi, khususnya dalam hal berbuat dosa. Walaupun identitasnya sebagai pengikut Kristus, namun kecenderungan berbuat dosa pasti masih ada. Untuk itu, orang-orang percaya perlu setiap saat memberikan penyerahan diri yang total kepada Allah, sehingga kehidupan mereka dapat menghasilkan buah-buah yang baik (Gal. 5:-22-23). ${ }^{5}$

Dengan demikian dapat disimpulkan bahwa, orang-orang percaya yang telah diselamatkan Allah, akan menghasilkan buah-buah yang baik dalam kehidupannya. Karena hal tersebut adalah bukti sebagai tanda bahwa dia adalah orang yang telah sungguhsungguh percaya dan menerima keselamatan tersebut. Untuk itu, agar setiap orang Kristen mempunyai pemahaman jaminan keselamatan yang sesuai dengan ajaran Alkitab, penulis merasa penting untuk menganalisis Injil Yohanes 10:28-29 serta membuat implikasinya bagi

${ }^{1}$ Yunardi Kristian Zega, "Radikalisme Agama Dalam Perspektif Alkitab Dan Implikasinya Bagi Pendidikan Agama Kristen," Jurnal Shanan 4, no. 1 (March 1, 2020): 1-20, http://ejournal.uki.ac.id/index.php/shan/article/view/1765.

2 Maria Widiastuti, "Konsep Keselamatan dalam Ajaran Calvinisme," Jurnal Pionir 5, no. 4 (2019): 288-296.

${ }^{3}$ Michael L. Brown, Hyper-Grace: Exposing the Dangers of the Modern Grace Message (America: Charisma Media, 2014), 17-20.

4 David Eko Setiawan, "Refleksi Pastoral terhadap Konsep Keselamatan dalam Universalisme Ditinjau dari Soteriologi Kristen," Fidei: Jurnal Teologi Sistematika dan Praktika 1, no. 2 (2018): 250-269, https://doi.org/10.34081/270031.

${ }^{5}$ Nurnilam Sarumaha, "Pengudusan Progresif Orang Percaya Menurut 1 Yohanes 1:9," KURIOS (Jurnal Teologi dan Pendidikan Agama Kristen) 5, no. 1 (2019): 1-11. 
pendidikan agama Kristen yang ada di keluarga, sekolah, maupun gereja. Dengan tujuan, agar setiap orang-orang percaya yang telah menerima keselamatan tersebut, dapat bertanggung jawab atas keselamatannya (Fil. 2:12-18).

\section{Metode Penelitian}

Artikel ini merupakan penelitian kualitatif yang bersifat kajian literature terhadap teks Alkitab dalam Injil Yohanes 10:28-29. Metode yang digunakan adalah deskriptif analisis, di mana teks dalam Yohanes 10:28-29 digunakan untuk mendeskripsikan konsep soteriologi. Teks tersebut dianalisis dengan pendekatan eksegetis sehingga diperoleh pemahaman tentang jaminan keselamatan yang sesuai dengan kebenaran yang ada di dalam ayat tersebut. Adapun fokus, sub fokus, dan sub-sub fokus yang akan dianalisis dalam Injil Yohanes 10:28-19, dapat dilihat dalam tabel berikut ini:

Tabel 1. Fokus, Sub Fokus, dan Sub-Sub Fokus Injil Yohanes 10:28-29

\begin{tabular}{|c|c|c|}
\hline Fokus & Sub Fokus & Sub-Sub Fokus \\
\hline \multirow[t]{2}{*}{$\begin{array}{l}\text { Jaminan } \\
\text { Keselamatan } \\
\text { Menurut Injil } \\
\text { Yohanes 10:28-29 }\end{array}$} & $\begin{array}{l}\text { Orang percaya } \\
\text { mempunyai jaminan } \\
\text { keselamatan (ayat. 28) }\end{array}$ & $\begin{array}{l}\text { 1. Yesus memberikan hidup yang kekal. } \\
\text { 2. Orang percaya tidak akan binasa. } \\
\text { 3. Orang percaya mempunyai jaminan } \\
\text { keselamatan. }\end{array}$ \\
\hline & $\begin{array}{l}\text { Allah adalah } \\
\text { sumber keselamatan } \\
\text { (ayat. 29) }\end{array}$ & $\begin{array}{l}\text { 1. Allah memberi jaminan keselamatan } \\
\text { melalui Yesus. } \\
\text { 2. Allah menjamin keselamatan orang } \\
\text { percaya. }\end{array}$ \\
\hline
\end{tabular}

Untuk memperdalam refleksi hasil dari analisis tulisan ini, penulis terlebih dahulu akan membahas mengenai terminologi keselamatan di masa Perjanjian Lama dan Perjanjian Baru. Setelah menganalisis Injil Yohanes 10:28-19, penulis juga akan membuat implikasinya bagi Pendidikan Agama Kristen (PAK) di keluarga, sekolah, dan gereja.

\section{Hasil dan Pembahasan}

Terminologi Keselamatan dalam Masa Perjanjian Lama dan Masa Perjanjian Baru Masa Perjanjian Lama (PL)

Istilah dalam bahasa Ibrani yang menjelaskan konsep keselamatan di masa Perjanjian Lama (PL) adalah kata Yasha. Yasha berarti lebar atau luas, lawan dari kesempitan atau tindasan. Artinya, kebebasan dari sesuatu yang mengikat atau membatasi, dan kemudian berarti pembebasan, pelepasan atau memberikan keluasan dan kelapangan kepada sesuatu. ${ }^{6}$ Oleh sebab itu, salah satu cara yang dilakukan orang-orang di masa PL agar memperoleh keselamatan dengan cara melakukan korban bakaran.

Konsep keselamatan melalui korban bakaran dilakukan dengan darah korban sembelihan. Herbert Wolf mengatakan, pada waktu korban-korban dipersembahkan, manusia ingin mendekati Allah dengan harapan bahwa korbannya diterima dan dosadosanya dapat diampuni. Pendamaian dengan Allah adalah tujuan orang yang menyembah Allah, untuk memenuhi tuntutan murka dari Allah yang kudus. Dalam beberapa hal,

${ }^{6}$ Charles C. Ryrie, Teologi Dasar 2 (Yogyakarta: ANDI Offset, 1991), 18. 
kematian seekor binatang melalui korban menjadi suatu tebusan untuk menyelamatkan nyawa orang yang telah membawa korban tersebut. ${ }^{7}$

Adapun beberapa macam korban di masa PL dan tujuan dari korban tersebut yang dapat diketahui, antara lain: pertama, korban bakaran yaitu, dengan ciri-ciri khusus di mana seluruh korban dibakar untuk menandakan pengudusan yang sempurna (Ibr. 10:1-3,10,11). Kedua, korban keselamatan yaitu sebuah korban sukarela, di mana sebagian dari binatang korban tersebut dimakan oleh imam dan orang yang membawa korban, hal ini menandakan hubungan antara Allah dengan manusia (Ef. 2:13,14). Ketiga, korban penghapus dosa, korban ini dipersembahkan akibat perbuatan dosa yang tidak disengaja (Yoh. 1:29; 6:51). Keempat, korban sajian atau penebus salah, apabila seseorang melanggar hak orang lain, maka dia harus mempersembahkan korban ini dan memberikan pengganti kerugian (Kol. 2:13). Korban sajian terdiri hasil ladang dari pekerjaan manusia (Im. 2:1-16; 6:14-23). ${ }^{8}$ Jadi, setiap korban persembahan mempunyai tujuan yang berbeda-beda dan dapat dibagi ke dalam dua jenis yaitu, korban dengan menggunakan darah hewan dan korban yang tidak menggunakan darah hewan. Korban yang menggunakan darah hewan antara lain, korban bakaran, korban keselamatan, korban pengapus dosa dan korban penebus salah, sedangkan korban yang tidak menggunakan darah hewan yaitu korban sajian, dikarenakan korban yang dipersembahkan tersebut terdiri dari hasil ladang atau kebun.

Orang-orang di masa PL meyakini bahwa, dengan memberikan persembahan korban tersebut, dosa mereka akan dihapus dan didamaikan dengan Allah. Namun pada akhirnya, terlihat bahwa ketidakmampuan korban-korban tersebut untuk menghasilkan kekudusan seperti yang dilambangkan. Karena korban tersebut bukanlah korban yang sesungguhnya yang dapat mendamaikan dosa manusia dengan Allah, akan tetapi hanyalah merupakan bayangan dari kenyataan yang akan datang. Berarti, usaha manusia agar memperoleh keselamatan dengan melaksanakan persembahan korban tidaklah menyelamatkan, karena yang dimaksud korban dalam PL mengenai domba yang tidak ada cacatnya, ini merupakan gambaran dari Yesus Kristus yang akan datang. Itulah Anak Domba YAHWEH yang tidak ada cacatnya (Yoh 1:29; Ibr 9:12-15). ${ }^{9}$ Dengan kata lain, persembahan korban-koran pada masa PL merupakan tipologi kepada Yesus Kristus yang akan datang sebagai korban yang sempurna dan bersifat kekal untuk menebus dosa-dosa umat manusia.

Charles C. Ryrie mengatakan bahwa, Iman adalah syarat utama untuk mendapatkan keselamatan di masa Perjanjian Lama dan di masa Perjanjian Baru. Abraham percaya kepada Allah dan Allah memperhitungkan hal itu kepadanya sebagai kebenaran (Kej. 15:6). Awalan Beth dalam bahasa Ibrani menunjukkan bahwa Abraham menaruhkan imannya dengan penuh keyakinan kepada Allah (band. Kel. 14:31; Yun. 3:5). Sama halnya dengan hubungan perjanjian yang ditetapkan oleh Musa terhadap bangsa Israel, yang artinya bahwa bangsa Israel juga harus mempunyai iman kepada Allah dalam perjanjian tersebut, agar mereka juga berkenan dihadapan Allah. ${ }^{10}$

Di dalam PL, selain Abraham dan Musa yang diselamatkan melalui iman kepada Allah, adapun beberapa tokoh Alkitab PL lainnya antara lain: Habel, "karena iman Habel telah mempersembahkan kepada Allah korban yang lebih baik dari korban Kain" (Ibr. 11:4). Henokh, "karena iman Henokh terangkat, supaya dia tidak mengalami kematian, dan ia

${ }^{7}$ Herbert Wolf, Pengenalan Pentateukh (Malang: Gandum Mas, 2004), 226-227.

8 Ani Teguh Purwanto, "Arti Korban Menurut Kitab Imamat," Journal Kerusso 2, no. 2 (September 5, 2017): 8-14, http://jurnal.sttiisurabaya.ac.id/index.php/Kerusso/article/view/Kerusso.

${ }^{9}$ Thuan Ong and Imanuel Zai, "Memahami Konsep Penebusan Dalam Hukum Taurat Dan Penggenapannya Dalam Diri Yesus Kristus," Jurnal Teologi Pondok Daud 6, no. 1 (2020): 1-7.

${ }^{10}$ Ryrie, Teologi Dasar 2, 18. 
tidak ditemukan, karena Allah telah mengangkatnya" (Ibr. 11:5). Nuh, "karena iman maka Nuh dengan petunjuk Allah tentang sesuatu yang belum kelihatan dengan taat mempersiapkan bahtera untuk menyelamatkan keluarganya" (Ibr. 11:7). Rahab "karena iman maka Rahab, perempuan sundal itu, tidak turut binasa bersama-sama dengan orangorang durhaka, karena ia telah menyambut pengintai-pengintai itu dengan baik" (Ibr. 11:31), dan masih banyak lagi tokoh-tokoh Alkitab lainnya di dalam PL yang diselamatkan karena mereka memiliki iman yang benar.

Jadi, konsep keselamatan di masa PL adalah iman kepercayaan kepada Allah bukan melalui persembahan korban-korban yang dibuat oleh manusia. Abraham Park mengatakan, perjanjian yang sangat penting harus digenapi melalui orang-orang percaya yang sungguhsungguh mengharapkan kerajaan Allah dan percaya kepada Yesus Kristus, siapa saja yang percaya akan janji-Nya mereka adalah keturunan Abraham secara rohani, karena dengan iman orang-orang percaya dapat diselamatkan. ${ }^{11}$ Dengan kata lain, Abraham diselamatkan oleh imannya, sehingga Allah memperhitungkan tersebut sebagai suatu kebenaran. Abraham disebut sebagai Bapa orang beriman, itulah sebabnya barang siapa yang memiliki iman yang sama seperti Abraham, dia juga akan diselamatkan.

\section{Masa Perjanjian Baru (PB)}

Keselamatan di masa PB berfokus pada pengorbanan Yesus Kristus yang telah mati di kayu salib. Pengorbanan yang dikerjakan oleh Kristus adalah satu-satunya sarana keselamatan. Di dalam hikmat-Nya yang tidak terbatas, Allah tidak merancang sarana keselamatan selain melalui darah yang dicurahkan oleh Yesus Kristus.12 Sama seperti dalam masa PL, inisiatif keselamatan tersebut sepenuhnya dari Allah (Yoh. 3:16).

Yesus Kristus dalam pengajaran-Nya menyatakan bahwa, diri-Nya sudah menggenapi nubuatan di dalam kitab-kitab para nabi, di mana berpusat kepada Mesias yang akan datang untuk menyelamatkan umat Allah. Yesus juga menyatakan bahwa, diri-Nya sendiri sebagai pembawa kabar baik tersebut, yang menjadi satu-satunya jalan untuk memperoleh keselamatan. ${ }^{13}$ Adapun beberapa cerita di dalam Alkitab, di mana Yesus menyatakan bahwa Dirinya sebagai Mesias yang dinubuatkan, antara lain: pertama, cerita percakapan antara Yesus dengan Nikodemus (Yoh 3:1-15). Kedua, dalam percakapan Yesus dengan perempuan Samaria (Yoh. 4:1-42). Ketiga, di dalam Injil Yohanes pasal 6, di mana Yesus menyatakan diri-Nya sebagai roti rohani yang sanggup memuaskan jiwa yang lapar. Keempat, di dalam Lukas 7:47-48, Yesus menyatakan bahwa Dirinya mempunyai kuasa untuk mengampuni dosa setiap orang yang bertobat. Kelima, dalam Yohanes pasal 10, Yesus menyatakan bahwa Dialah satu-satunya pintu keselamatan tersebut, dan tidak seorangpun akan selamat, tanpa melalui-Nya.

Rasul Paulus merupakan salah satu tokoh besar yang sangat giat dalam memberitakan kabar keselamatan melalui Yesus Kristus. Di dalam kitab Roma 1:1 pada bagian ini menjelaskan bahwa, Rasul Paulus sedang menyatakan dirinya sebagai seseorang yang dipanggil Allah untuk menyampaikan kabar Injil tentang Yesus Kristus. Rasul Paulus mengartikan Injil Kristus sebagai sebuah kabar kesukaan tentang keselamatan bagi setiap orang-orang berdosa. Inti dari setiap fokus khotbah dan pengajaran Paulus, konsisten dan

${ }^{11}$ Abraham Park, Pertemuan Yang Terlupakan (Jakarta: Yayasan Damai Sejahtera Utama, 2011), 50-51.

${ }^{12}$ G.J. Baan, TULIB : Lima Pokok Calvinisme (Surabaya: Momentum, 2010), 82.

${ }^{13}$ Jonar Situmorang, 7 Jesus' Statements (Yogyakarta: ANDI Offset, 2011), 137. 
terpusat pada hal yang dikerjakan Allah melalui Yesus Kristus. ${ }^{14}$ Pada waktu memberitakan ajaran Injil, Paulus memberitakan kabar keselamatan ke berbagai suku bangsa, Paulus tidak membeda-bedakan antara orang Yahudi dan orang Yunani karena Paulus mengetahui bahwa Allah murah hati bagi semua orang yang berseru kepada-Nya. Dengan demikian, Paulus juga menginginkan semua orang agar dapat mendengar kabar baik (keselamatan) yang berasal dari Yesus Kristus tersebut.

Berdasarkan uraian di atas tentang konsep keselamatan di masa Perjanjian Lama dan masa Perjanjian Baru dapat disimpulkan bahwa, keselamatan dari Allah hanya berpusat kepada Yesus Kristus sebagai Juruselamat umat manusia. Di mana pada masa Perjanjian Lama, keselamatan tersebut berpusat pada janji Allah kepada Mesias yang akan datang, sedangkan pada masa Perjanjian Baru keselamatan tersebut berpusat pada janji Allah kepada Mesias yang telah datang melalui Yesus Kristus.

\section{Jaminan Keselamatan dalam Injil Yohanes 10:28-29}

Di dalam nats Yohanes 10:28-29, dapat dilihat bahwa ada jaminan keselamatan yang Allah berikan melalui Yesus Kristus. Oleh karena itu, supaya dapat lebih mengetahui makna sesungguhnya dari perkataan Yesus tersebut, penulis akan menganalisis Injil Yohanes 10:2829, sebagai berikut:

\section{Orang Percaya Menerima Jaminan Keselamatan (Ayat 28)}

Dalam Injil Yohanes 10:28 Yesus mengatakan, Dia memberikan hidup yang kekal kepada setiap orang-orang yang percaya kepada-Nya, dan orang-orang yang percaya tersebut tidak akan binasa sampai selama-lamanya dan Yesus menjaminnya, seperti itulah kira-kira maksud dari ayat tersebut. Oleh sebab itu, agar dapat menemukan makna yang lebih luas, penulis akan menganalisis ayat tesebut ke dalam 3 (tiga) sub fokus, antara lain: 1) Yesus memberikan hidup yang kekal, 2) Orang percaya tidak akan binasa, dan 3) Orang percaya mempunyai jaminan keselamatan.

\section{Yesus Memberikan Hidup Yang Kekal}

Injil Yohanes 10:28a berkata "dan Aku memberikan hidup yang kekal kepada

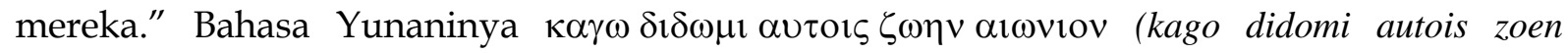
aionion). Kata yang digunakan untuk istilah memberikan adalah didomi. Kata yang digunakan untuk istilah zoen artinya hidup. Kata aionion artinya yang kekal. ${ }^{15}$ Kalimat yang berkata dalam Yohanes 10:28a merupakan bentuk kata kerja untuk waktu sekarang (present) yang artinya bahwa orang-orang percaya atau umat Allah sudah memiliki kehidupan kekal pada saat itu juga. ${ }^{16}$ Dengan demikian, ketika seseorang tersebut telah menerima Yesus Kristus dalam hidupnya, pada saat itu juga ia sudah memiliki kehidupan kekal.

Yesus Kristus memberikan kehidupan yang kekal bagi setiap orang percaya agar mereka diselamatkan dari hukuman Allah (Rm. 6:23). Kehidupan kekal yang Yesus berikan merupakan anugerah dan kasih karunia yang cuma-cuma (Rm. 3:24). Matthew mengatakan, anugerah tersebut tidak diperjual belikan dengan harga yang tinggi, melainkan diberikan oleh kasih karunia melalui Yesus Kristus. Untuk itu, Yesus Kristus berkuasa untuk

${ }_{14}$ Aya Susanti, "Keselamatan Dalam Konsep Rasul Paulus," Integritas: Jurnal Teologi 1, no. 1 (June 27, 2019): 15-28, http://journal.sttjaffrayjakarta.ac.id/index.php/JI/article/view/8.

${ }^{15}$ Hasan Susanto, Perjanjian Baru Interlinear Yunani-Indonesia Dan Konkordasi Perjanjian Baru (Jakarta: Lembaga Alkitab Indonesia, 2006), 549.

${ }^{16}$ Guthrie, Tafsiran Alkitab Masa Kini 3 Matius-Wahyu, 303. 
memberikannya kepada siapa saja yang percaya kepada-Nya (Yoh. 17:2). ${ }^{17}$ Jadi, berdasarkan uraian di atas dapat dilihat bahwa, Yesus Kristus akan langsung (pada saat itu juga) memberikan hidup kekal bagi setiap orang yang percaya kepada-Nya.

\section{Orang Percaya Tidak Akan Binasa}

Dalam Injil Yohanes 10:28b mengatakan "dan mereka pasti tidak akan binasa sampai

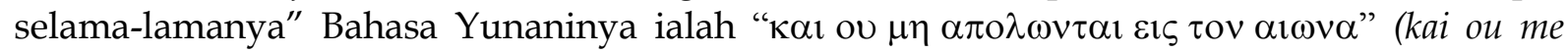
apolontai eis ton aiona). Kata yang digunakan untuk istilah ou me artinya pasti tidak. Kata apolontai artinya mereka akan menjadi binasa, bentuk dari kalimat ini ialah; kata kerja, orang ketiga, jamak, aorist, tengah, subjunctive. ${ }^{18}$ Maksud dari nats ini ialah, melalui kematian Yesus Kristus mendatangkan kehidupan kekal bagi setiap orang percaya, yaitu pengampunan atas dosa-dosa. Oleh sebab itu, kehidupan kekal membuat orang-orang percaya terlepas dari kebinasaan yang kekal, sehingga segala sesuatu yang akan memisahkan orang-orang percaya dengan keselamatan yang berasal dari Allah telah disingkirkan oleh pengorbanan Yesus Kristus yang mati di kayu salib, karena kematian Yesus Kristus telah memberikan orang-orang percaya pengampunan dosa. ${ }^{19}$

Kalau melihat kembali konsep keselamatan di masa Perjanjian Lama, orang-orang pada waktu itu menggunakan korban bakaran untuk mencari keselamatannya. Namun, korban-korban tersebut tidaklah pernah dapat membebaskan mereka dari dosa-dosanya. Karena persembahan korban bakaran yang mereka lakukan pada waktu itu, tidaklah sempurna di hadapan Allah. Untuk itu, korban yang sempurna di hadapan Allah hanyalah melalui pengorbanan Yesus Kristus (Yoh. 3:16). Jadi, orang-orang percaya tidak akan binasa karena Yesus Kristus adalah korban sempurna yang dapat membebaskan manusia dari dosa-dosanya.

\section{Orang Percaya Mempunyai Jaminan Keselamatan}

Bagian akhir dari ayat 28 dalam Injil Yohanes pasal 10 mengatakan "dan seorang pun tidak akan merebut mereka dari tangan-Ku." Bahasa Yunaninya

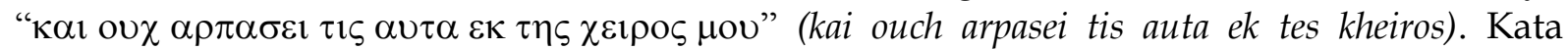
yang digunakan untuk istilah ouch artinya tidak. Kata arpasei artinya akan merebut, bentuk kata yang digunakan ialah kata kerja, orang ketiga, tunggal, masa depan (yang akan datang), aktif, indikatif. Kata yang digunakan untuk istilah kheiros artinya tangan (yang berkuasa). ${ }^{20}$ Jadi, maksud perkataan Yesus "seorang pun tidak akan merebut mereka dari tangan-Ku," Yesus memberikan jaminan keamanan bagi setiap orang-orang percaya sampai masa yang akan datang, ${ }^{21}$ karena tangan Yesus adalah tangan yang berkuasa yang dapat menghadapi perlawanan dari siapa pun, untuk menjaga dan melindungi setiap umat-Nya.

Matthew mengatakan, para gembala yang memiliki domba dalam jumlah yang banyak sering kehilangan domba-dombanya dan menyaksikan kebinasaan dari dombadombanya tersebut. Namun, Yesus Kristus menegaskan bahwa tidak satu pun dari dombadomba-Nya (orang percaya) yang akan hilang dari-Nya. Artinya bahwa, tidak ada satupun

723.

17 Matthew Henry, Tafsiran Matthew Henry Injil Yohanes 1-11 (Surabaya: Momentum, 2010),

18 Susanto, Perjanjian Baru Interlinear Yunani-Indonesia Dan Konkordasi Perjanjian Baru, 549.

${ }_{19}$ Desti Samarenna, "Konsep Soteriologi Menurut Efesus 2:1-10," FIDEI: Jurnal Teologi

Sistematika dan Praktika 2, no. 2 (December 10, 2019): 247-264, http://www.stt-tawangmangu.ac.id/ejournal/index.php/fidei/article/view/54.

${ }^{20}$ Susanto, Perjanjian Baru Interlinear Yunani-Indonesia Dan Konkordasi Perjanjian Baru, 549.

${ }^{21}$ Guthrie, Tafsiran Alkitab Masa Kini 3 Matius-Wahyu, 303. 
dari orang-orang percaya akan mengalami kebinasaan.22 Yesus Kristus menjamin keselamatan setiap orang percaya seperti gembala domba yang sangat ketat di dalam menjaga domba-domba-Nya agar tidak ada yang dapat merebut atau mencurinya. Yesus juga menegaskan bahwa, orang-orang percaya ada dalam genggaman tangan-Nya dan di bawah perlindungan-Nya (Ul. 33:3). Dengan kata lain, inilah jaminan keselamatan dari Yesus bagi setiap orang-orang percaya sehingga mereka tidak akan binasa sampai selamalamanya.

\section{Allah Adalah Sumber Keselamatan (Ayat 29)}

Allah adalah sumber keselamatan bagi orang-orang percaya. Dalam Injil Yohanes 10:29 menjelaskan, Allah memberikan jaminan keselamatan melalui Yesus Kristus dan Allah juga ikut menjamin keselamatan tersebut. Oleh sebab itu, agar dapat menemukan makna yang lebih luas, penulis akan menganalis ke dalam 2 (dua) sub fokus, antara lain: 1) Allah memberikan jaminan keselamatan melalui Yesus Kristus, dan 2) Allah menjamin keselamatan orang percaya.

\section{Allah Memberi Jaminan Keselamatan Melalui Yesus Kritus}

Injil Yohanes 10:29a menjelaskan, "Bapa-Ku, yang memberikan mereka kepada-Ku, lebih besar dari siapa pun." Dalam bahasa Yunaninya ialah o $\pi \alpha \tau \eta \rho \mu$ ov o $\delta \varepsilon \delta \omega \kappa \varepsilon v \mu$ oı $\pi \alpha \nu \tau \omega \nu \mu \varepsilon ı \zeta$ ov $\varepsilon \sigma \tau \iota \nu$ (o pater mou o dedoken moi panton meizon estin).23 Bruce M. Metzger mengatakan "my Father," by hyperbaton, functions as subject of $\delta \varepsilon \delta \omega \kappa \varepsilon v$ within the relative clause, best explains the origin of the other readings." 24 Artinya ialah, kalimat Bapa-Ku berfungsi sebagai subjek di dalam klausa relatif dan sangat baik dalam menjelaskan asal bacaan lainnya. Jadi, maksud dalam nast tersebut sedang menjelaskan bahwa Allah sangat mengasihi manusia, sehingga Ia memberikan kuasa keselamatan yang sangat besar tersebut melalui Yesus Kristus yang telah dijanjikan-Nya (Yoh.3:16). Kuasa keselamatan orang-orang percaya yang diberikan Allah melalui Yesus Kristus tidaklah mereka jagai sendiri, melainkan tangan Yesus Kristus sendiri yang menjaganya. ${ }^{25}$ Oleh sebab itu, di dalam nast ini dapat dilihat bahwa, Yesus juga memastikan kepada orang-orang percaya bahwa Dia akan menjaga mereka yang telah diberikan Allah Bapa kepada-Nya, sehingga tidak satupun dari orang percaya yang akan binasa.

\section{Allah Menjamin Keselamatan Orang Percaya}

Dalam Injil Yohanes 10:29b menyatakan "dan seorang pun tidak akan merebut mereka dari tangan Bapa." Dalam bahasa Yunaninya ialah

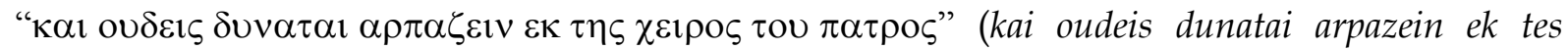
kheiros tou patros).26 Kata yang dipakai untuk istilah arpazein yang artinya merebut, bentuknya ialah kata kerja, waktu sekarang, aktif, infinitif. Infinitif merupakan kata benda verbal yaitu kata yang berfungsi ganda, baik sebagai kata kerja maupun kata benda. Jadi, sebagai kata kerja dan kata benda, infinitif memiliki kala dan diatesis yang layak menerima

22 Henry, Tafsiran Matthew Henry Injil Yohanes 1-11, 724.

${ }^{23}$ Susanto, Perjanjian Baru Interlinear Yunani-Indonesia Dan Konkordasi Perjanjian Baru, 549.

${ }^{24}$ Bruce M. Metzger, A Textual Commentary On The Greek New Testament (Stuttgart: German Bible Society, 2012), 197.

${ }^{25}$ Jonathan Slater, "Salvation as Participation in the Humanity of the Mediator in Calvin's Institutes of the Christian Religion : A Reply to Carl Mosser," Scottish Journal of Theology 58, no. 1 (February 14, 2005): 39-58,

https://www.cambridge.org/core/product/identifier/S003693060500092X/type/journal_article.

${ }^{26}$ Susanto, Perjanjian Baru Interlinear Yunani-Indonesia Dan Konkordasi Perjanjian Baru, 549. 
subjek dan objek, kedua-duanya adalah kata benda atau kata ganti dalam bentuk aktif. Infinitif dalam Injil Yohanes 10:29 dari kata arpazein berkaitan dengan waktu sekarang (present) yang di mana sedang menekankan aspek atau tindakan yang tengah berlangsung. ${ }^{27}$ Jadi, maksud dari nast tersebut sedang menjelaskan bahwa, Allah Bapa selalu mempertahankan pemberian-Nya tersebut, sehingga umat-Nya tidak perlu kuatir akan keamanan keselamatannya. Apalagi keamanan tersebut diperkuat lagi oleh kenyataan bahwa umat-Nya itu adalah pemberian dari Allah kepada Anak-Nya, sehingga tidak ada keamanan lain yang lebih besar dari hal tersebut. ${ }^{28}$ Dengan kata lain, kuasa keselamatan yang Allah Bapa berikan kepada Yesus Kristus, Allah Bapa juga ikut menjaminnya.

Matthew Henry mengatakan, walaupun segala kekuatan yang ada di dunia dan segala kekuatan yang dimiliki oleh Iblis di neraka bersatu untuk berusaha menggagalkan keselamatan orang-orang percaya, tetap saja mereka tidak akan bisa, karena keselamatan yang Yesus berikan kepada orang-orang percaya, Allah juga ikut menjamin, sehingga keselamatan orang-orang percaya benar-benar aman dan tidak akan hilang oleh kuasa apapun. ${ }^{29}$

Berdasarkan hasil analisis Injil Yohanes 10:28-29 dapat disimpulkan bahwa, Yesus Kristus memberikan keselamatan yang bersifat kekal bagi setiap orang percaya. Yesus juga menjamin hal tersebut karena keselamatan tersebut adalah pemberian Allah Bapa agar umat manusia yang berdosa tidak mengalami kebinasaan. Allah Bapa juga menjamin hal tersebut, barang siapa yang percaya kepada anak-Nya Yesus Kristus, orang tersebut tidak akan binasa sampai selama-lamanya.

Dengan demikian, apakah sebagai orang percaya yang sudah menerima Yesus Kristus dan beroleh keselamatan kekal dapat sebebas-bebasnya untuk melakukan dosa. Dalam Injil Yohanes 10:27, Yesus berkata "Domba-domba-Ku mendengarkan suara-Ku dan Aku mengenal mereka dan mereka mengikut aku." Dalam nats ini sedang menjelaskan bahwa, Yesus dapat membedakan mana orang percaya sungguh-sungguh dan mana orang percaya palsu. Orang percaya sungguh-sungguh pasti mendengarkan perintah yang diajarkan-Nya. Yesus berkata dalam Injil Yohanes 16:13 bahwa Roh Kudus akan memimpin orang percaya kepada kebenaran, agar mereka dapat hidup dalam ketaatan dan kekudusan yang sesuai dengan Firman Allah. Selain itu, Roh kudus juga akan menuntun orang percaya yang telah berdosa untuk kembali ke jalan yang benar. ${ }^{30}$ Jadi, hasil dari orang percaya sungguh-sungguh adalah orang yang hidup seturut dengan kehendak Firman Allah, di mana orang tersebut akan menghasilkan buah-buah roh yang baik di dalam kehidupannya (Gal. 5:22-23).

\section{Implikasi}

Adapun hal-hal yang perlu dilaksanakan oleh para pendidik, baik yang mengajar di keluarga (orang tua), sekolah (guru PAK), dan gereja (Pendeta dan para pelayan) dalam mengajarkan doktrin soteriologi tentang jaminan keselamatan, antara lain: pertama, para pendidik di keluarga, sekolah, dan gereja perlu membawa setiap naradidik yang diajar untuk berpikir kritis, khususnya mengenai Doktrin Soteriologi. Oleh karena itu, para pendidik juga harus mau belajar dan mau berpikir kritis dalam mempelajari doktrin

${ }^{27}$ Welly Pandensolang, Sintaks Bahasa Yunani Perjanjian Baru (Jakarta: sekolah tinggi theologia agapes Indonesia, 2007), 50.

${ }_{28}$ Guthrie, Tafsiran Alkitab Masa Kini 3 Matius-Wahyu, 303.

${ }^{29}$ Henry, Henry Matthew Henry Injil Yohanes 1-11, 725.

${ }^{30}$ Arifianto, Yonatan Alex, and Asih Rachmani Endang Sumiwi, "Peran Roh Kudus Dalam Menuntun Orang Percaya Kepada Seluruh Kebenaran Berdasarkan Yohanes 16: 13," DIEGESIS: Jurnal Teologi Kharismatika 3, no. 1 (2020): 1-12. 
soteriologi, khususnya tentang jaminan keselamatan, sehingga menjauhkan para pendidik dari pengajaran yang dapat menyesatkan orang-orang yang mereka didik. ${ }^{31}$ Kedua, di gereja dan di sekolah perlu membuat kurikulum yang berorientasi kepada doktrin soteriologi, khususnya mengenai jaminan keselamatan, sehingga jemaat di gereja dan siswa-siswi yang ada di sekolah, mendapat pemahaman yang sesuai dengan ajaran Akitab.32 Selain itu, dengan adanya kurikulum tersebut, perlu untuk menumbuhkan rasa tanggung jawab akibat dari keselamatan kekal yang mereka telah peroleh, sehingga setiap naradidik mempunyai komitmen yang kuat untuk hidup sesuai dengan ajaran Firman Tuhan.

Ketiga, pendidik di keluarga, sekolah, dan gereja perlu untuk menjelaskan kepada naradidik tentang peran Roh Kudus terhadap orang yang menerima Keselamatan. Di mana Roh Kudus akan memampukan setiap orang percaya (yang telah menerima Keselamatan) untuk dapat melakukan apa yang dikehendaki Allah dalam kehidupan pribadi mereka. Keempat, di dalam keluarga, orang tua juga perlu untuk membuat waktu sharing yang diatur secara terjadwal untuk membahas tentang jaminan keselamatan yang kekal (Doktrin Soteriologi). Dengan tujuan agar setiap anggota keluarga dapat saling bertukar pendapat, sehingga yang belum paham dapat menjadi paham, dan yang sudah paham akan menjadi lebih paham lagi. Kelima, para pendidik di keluarga, sekolah, maupun gereja perlu untuk memastikan bahwa naradidik yang mereka ajar, sudah benar-benar memahami dengan baik tentang Jaminan Keselamatan kekal dalam Yesus Kristus, sehingga naradidik tidak akan mudah terpengaruh oleh para pendidik yang tidak bertanggjawab dalam memaparkan ajaran Kekristenan yang salah dan bertentangan dengan keyakinan iman Kristen.

\section{Rekomendasi untuk Penelitian Lanjutan}

Jaminan keselamatan bagi orang percaya (Kristen) merupakan anugerah terbesar dari Allah. Oleh sebab itu, penelitian selanjutnya dapat mengembangkan tentang tugas dan tanggung jawab sebagai orang percaya, serta mengkaji peran Roh Kudus dalam memimpin dan membimbing orang percaya hidup dalam kebenaran. Pembahasan lanjutan ini akan menarik dalam memperkaya kajian-kejian tentang kehidupan orang percaya dan keselamatan.

\section{Kesimpulan}

Injil Yohanes 10:28-29 menjelaskan, Yesus Kristus telah memberikan hidup yang kekal kepada orang-orang yang percaya kepada-Nya dan mereka yang percaya pasti tidak akan binasa sampai selama-lamanya, karena mereka memiliki jaminan keselamatan dari Yesus dan juga Allah yang adalah sumber keselamatan. Namun, jaminan keselamatan tersebut bukanlah membebaskan orang-orang percaya untuk melakukan dosa dengan sebebas-bebasnya, melainkan orang percaya sungguh-sungguh adalah orang yang hidup seturut dengan kehendak Firman Allah. Oleh karena Roh Kudus ada di dalam diri setiap orang percaya, sehingga mereka dimampukan untuk melakukan kebenaran seperti yang dikehendaki Allah dalam kehidupannya. Untuk itu, agar setiap orang percaya dapat memiliki pemahaman yang baik dan benar mengenai jaminan keselamatan yang kekal tersebut. Hal ini perlu menjadi tanggung jawab para pendidik yang mengajarkan PAK, baik

${ }^{31}$ Nova Ritonga et al., "Implementasi Metode Problem Solving Dalam Meningkatkan Pembelajaran Pendidikan Agama Kristen Di Sekolah," Jurnal Shanan 5, no. 1 (2021): 29-42.

${ }^{32}$ Desi Sianipar et al., "Pelatihan Penyusunan Kurikulum Pendidikan Agama Kristen Remaja di HKBP Jatisampurna Bekasi," JURNAL ComunitÃ Servizio : Jurnal Terkait Kegiatan Pengabdian kepada Masyarakat, terkhusus bidang Teknologi, Kewirausahaan dan Sosial Kemasyarakatan 2, no. 2 (2 November 2020): 447-457, https://doi.org/10.33541/cs.v2i2.1964. 
di keluarga yaitu orang tua, di sekolah yaitu guru-guru PAK, dan di gereja yaitu pendeta dan para pelayannya.

\section{Rujukan}

Arifianto, Yonatan Alex, and Asih Rachmani Endang Sumiwi. "Peran Roh Kudus Dalam Menuntun Orang Percaya Kepada Seluruh Kebenaran Berdasarkan Yohanes 16: 13." DIEGESIS: Jurnal Teologi Kharismatika 3, no. 1 (2020): 1-12.

Baan, G.J. TULIB : Lima Pokok Calvinisme. Surabaya: Momentum, 2010.

BD, D. Guthrie. Tafsiran Alkitab Masa Kini 3 Matius-Wahyu. Jakarta: Yayasan Komunikasi Bina Kasih/OMF, 1982.

Brown, Michael L. Hyper-Grace: Exposing the Dangers of the Modern Grace Message. America: Charisma Media, 2014.

Henry, Matthew. Tafsiran Matthew Henry Injil Yohanes 1-11. Surabaya: Momentum, 2010.

Metzger, Bruce M. A Textual Commentary On The Greek New Testament. Stuttgart: German Bible Society, 2012.

Ong, Thuan, and Imanuel Zai. "Memahami Konsep Penebusan Dalam Hukum Taurat Dan Penggenapannya Dalam Diri Yesus Kristus." Jurnal Teologi Pondok Daud 6, no. 1 (2020): 1-7.

Pandensolang, Welly. Sintaks Bahasa Yunani Perjanjian Baru. Jakarta: sekolah tinggi theologia agapes Indonesia, 2007.

Park, Abraham. Pertemuan Yang Terlupakan. Jakarta: Yayasan Damai Sejahtera Utama, 2011.

Purwanto, Ani Teguh. "Arti Korban Menurut Kitab Imamat.” Journal Kerusso 2, no. 2 (September 5, 2017): 8-14. http://jurnal.sttiisurabaya.ac.id/index.php/Kerusso/article/view/Kerusso.

Ritonga, Nova, Juliandes Leonardo Trisno Mone, Mathan Yunip, and Yunardi Kristian Zega. "Implementasi Metode Problem Solving Dalam Meningkatkan Pembelajaran Pendidikan Agama Kristen Di Sekolah." Jurnal Shanan 5, no. 1 (2021): 29-42.

Ryrie, Charles C. Teologi Dasar 2. Yogyakarta: ANDI Offset, 1991.

Samarenna, Desti. “Konsep Soteriologi Menurut Efesus 2:1-10." FIDEI: Jurnal Teologi Sistematika dan Praktika 2, no. 2 (December 10, 2019): 247-264. http:/ / www.stttawangmangu.ac.id/e-journal/index.php/fidei/article/view/54.

Sarumaha, Nurnilam. "Pengudusan Progresif Orang Percaya Menurut 1 Yohanes 1:9." KURIOS (Jurnal Teologi dan Pendidikan Agama Kristen) 5, no. 1 (2019): 1-11.

Schultz, Samuel J. Pengantar Perjanjian Lama Taurat Dan Sejarah Kejadian-Ester. Malang: Gandum Mas, 1979.

Setiawan, David Eko. “Refleksi Pastoral Terhadap Konsep Keselamatan Dalam Universalisme Ditinjau Dari Soteriologi Kristen." Fidei: Jurnal Teologi Sistematika dan Praktika 1, no. 2 (2018): 250-269. http://www.stt-tawangmangu.ac.id/ejournal/index.php/fidei/article/view/ 8 .

Sianipar, Desi, Yunardi Kristian Zega, Luterius Nehe, and Kristiantoro. "Pelatihan Penyusunan Kurikulum Pendidikan Agama Kristen Remaja Di HKBP Jatisampurna Bekasi." JURNAL ComunitÃ Servizio : Jurnal Terkait Kegiatan Pengabdian kepada Masyarakat, terkhusus bidang Teknologi, Kewirausahaan dan Sosial Kemasyarakatan 2, no. 2 (November 2, 2020): 447-457.

http://ejournal.uki.ac.id/index.php/cs/article/view/1964.

Situmorang, Jonar. 7 Jesus' Statements. Yogyakarta: ANDI Offset, 2011.

Slater, Jonathan. "Salvation as Participation in the Humanity of the Mediator in Calvin's Institutes of the Christian Religion : A Reply to Carl Mosser." Scottish Journal of Theology 58, no. 1 (February 14, 2005): 39-58. 
https://www.cambridge.org/core/product/identifier/S003693060500092X/type/jo urnal_article.

Susanti, Aya. “Keselamatan Dalam Konsep Rasul Paulus." Integritas: Jurnal Teologi 1, no. 1 (June 27, 2019): 15-28.

http://journal.sttjaffrayjakarta.ac.id/index.php/JI/article/view/8.

Susanto, Hasan. Perjanjian Baru Interlinear Yunani-Indonesia Dan Konkordasi Perjanjian Baru. Jakarta: Lembaga Alkitab Indonesia, 2006.

Widiastuti, Maria. “Konsep Keselamatan Dalam Ajaran Calvinisme.” Jurnal Pionir 5, no. 4 (2019): 288-296.

Zega, Yunardi Kristian. "Radikalisme Agama Dalam Perspektif Alkitab Dan Implikasinya Bagi Pendidikan Agama Kristen." Jurnal Shanan 4, no. 1 (March 1, 2020): 1-20. http://ejournal.uki.ac.id/index.php/shan/article/view/1765. 